\title{
Investigation of the Main and Residual Risk Factors in the Success Rates of Premature Ventricular Contraction Ablation
}

\author{
Muhammed Keskin $\odot$, Süha Asal $\odot$, Selami Doğan, Tufan Çınar $\odot$, Murat Selçuk
}

Department of Cardiology, Sultan Abdulhamid Han Training and Research Hospital, Health Science University, İstanbul, Turkey

To the Editor,

We read with interest the paper by Kanat et al. (1) entitled "Effect of Echocardiographic Epicardial Adipose Tissue Thickness on Success Rates of Premature Ventricular Contraction Ablation." The authors evaluated the relationship between epicardial adipose tissue thickness and success rates of premature ventricular contraction (PVC) ablation. We had comments about this study (1).

Most patients with frequent ventricular premature complexes have no demonstrable cause, but structural heart diseases such as ischemic heart disease, valvular heart disease, cardiomyopathy, and ventricular hypertrophy are known to cause PVCs. In structurally normal hearts, they are present, albeit at a lower prevalence (2).

In searching for previous literature on the subject, we came across another study by Kırış et al. (3) who assessed the relation between epicardial adipose tissue and the disposition to frequent premature ventricular complexes. Kırış et al. (3) matched statistically equivalent but relatively small trial and control groups and concluded that an increase in frequent PVC formation can be seen in individuals with an increased epicardial adipose tissue thickness.

Myocardial damage, scarring, and the resulting disruption of the normal electrical conduction system of the heart are usually attributed as the causes of frequent PVC formation and the associated increase in mortality in structural heart disease (4). Epicardial adipose tissue mass and atherosclerotic plaque burden are both increased in individuals with increased body mass index and waist circumference (5).
We thought that this study can benefit from the addition of hypotheses explaining the relation between proposed decrease in ablation success and the mechanisms of alterations of the conduction system of the heart in individuals with an increased epicardial adipose tissue thickness.

Patient Consent for Publication: N/A.

Author Contributions: Concept - M.K., S.A., S.D., M.S., T.Ç.; Design - M.K., S.A.; Supervision - M.K., T.Ç.; Literature Search - M.K., S.A., S.D., M.S., T.Ç.; Writing - M.K., S.A.; Critical Review - M.K., S.D.

Conflict of Interest: The authors have no conflicts of interest to declare.

Funding: The authors declared that this study has received no financial support.

\section{REFERENCES}

1. Kanat S, Duran Karaduman B, Tütüncü A, Tenekecioğlu E, Mutluer FO, Akar Bayram N. Effect of echocardiographic epicardial adipose tissue thickness on success rates of premature ventricular contraction ablation. Balkan Med J 2019;36:324-30. [Crossref]

2. Lee V, Hemingway H, Harb R, Crake T, Lambiase P. The prognostic significance of premature ventricular complexes in adults without clinically apparent heart disease: A meta-analysis and systematic review. Heart 2012;98:1290-8. [Crossref]

3. Kırış A, Turan OE, Kırış G, İlter A, Öztürk M, Aydın M, et al. The relationship between epicardial fat tissue thickness and frequent ventricular premature beats. Kardiol Pol 2015;73:527-32. [Crossref]

4. Pedersen CT, Kay GN, Kalman J, Borggrefe M, Della-Bella P, Dickfeld T, et al. EHRA/HRS/APHRS expert consensus on ventricular arrhythmias. Heart Rhythm 2014;11:e166-96. [Crossref]

5. Gullaksen S, Funck K, Laugesen E, Hansen TK, Dey D, Poulsen PL. Volumes of coronary plaque disease in relation to body mass index, waist circumference, truncal fat mass and epicardial adipose tissue in patients with type 2 diabetes mellitus and controls. Diab Vasc Dis Res 2019;16:328-36. [Crossref] 